Rupantaran : A Multidisciplinary Journal

Vol. IV : pp 31-43, October, 2020

ISSN : 2091-0061

https://doi.org/10.3126/rupantaran.v4i1.34015

Research Management Cell (RMC)

Dhankuta Multiple Campus, Dhankuta

Tribhuvan University, Nepal

\title{
Food Security in Nepal: A Review
}

Badal Chemjong ${ }^{1}$

Yadav $\mathrm{KC}^{2}$

\section{Abstract}

Nepal has improved food security situation in recent years, but still considered as a poor country in the world. The main objective of this paper is to evaluate the food security situation in Nepal. Food insecurity in Nepal has been associated with susceptibility to natural disasters, such as drought, governance, earthquake, floods, and landslides, vulnerability to fluctuations in global prices, civil turmoil, disease and poor infrastructures. Pandemic COVID-19 is degrading the daily life of the people and driving to food insecurity in the country. Mostly western Nepal and Terai region seems to be more vulnerable to disasters and food insecurity. In Nepal, 4.6 million people are food-insecure, with 20 percent of household mildly food-insecure, 22 percent moderately food-insecure and 10 percent severely food-insecure. This problem needs to be solved by a clear and sound policies and strategy by putting natural resources conservation in consideration.

Key Words: current status, food security, hazard, landslide, malnutrition

\section{Introduction}

Food security is multidimensional in nature, which is defined by international organizations and researchers in different ways depending on their conditions and concerns. Earlier, in 80's food availability was mainly used as indicator of food security analysis, while household food sufficiency was indicator for food security measurement (Adhikari, 2010). According to FAO, (1996), food security is when all people, at all times, have physical, social and economic access to sufficient, safe and nutritious food which meets their dietary needs and food preferences for an active and healthy life. According to this definition, food security involves four pillars viz.

1. Ms. Chemjong is a Masters Students at Central Department of Food Technology, TU, Dharan, Nepal.

2. Mr. KC is a Lecturer at Central Campus of Technology, TU, Dharan, Nepal. Email: ykcdng504@, gmail.com 
availability, access, utilization and stability. Those four dimensions together are equally useful as a tool for food security analysis.

Nepal is diverse in culture, religion and geographically also so obviously food security and subsistence are affected by ecological belt and culture. Mostly rural area mainly in the remote and low productive areas where rain- fed subsistence agriculture is more pervasive, found to be more prevalent of food insecurity in Nepal. According to the $\mathrm{MoH},(2017)$, prevalence of severely food insecure population in rural area is $12 \%$ while in urban areas is $9 \%$. If we look at the prevalence of food insecurity as a mountain, hilly and terai zone, mountain and hilly zone are seems to be more prevalent of food insecurity than terai zone, $14 \%$ and $9 \%$ respectively in mountain and terai zone. Low farm productivity, limited livelihood opportunities and weak market connectivity caused by poor infrastructure, together with geographical heterogeneity, gender and caste disparities are considered as underlying causes of food insecurity and under nutrition in Nepal (MoALD et al., 2018) .

Nepal is among the world's poorest countries, ranking $148^{\text {th }}$ out of 189 , with a Human Development Index (HDI) score of 0.574 in 2019 (WFP, 2019). Susceptibility to natural disasters, such as drought, earthquakes, floods, landslides, vulnerability to fluctuations in global prices, civil unrest, also with pandemic disease like COVID-19, endemic disease like dengue and poor infrastructure drive food insecurity in the country. The Zero Hunger Strategic Review (ZHSR) conducted in 2017-18 found that the country still suffers from severe food insecurity and malnutrition. Mainly among young children, adolescents and new mothers are still very much prevalent of malnutrition in Nepal. Nepal has set a target to graduate from the status of a LDC by 2022, with a hopeful stride towards development.

Government of Nepal enacted 'Right to Food Act, 2018' which enshrines food as a fundamental right of every citizen, it is a powerful step towards meeting Nepal's commitment to rid the country of malnutrition, hunger and food security. The Constitution of Nepal 2015 defines Nepal as a federal democratic republic organized around three levels of government, federal, state and local. Hereafter, state is divided into seven provinces and local is divided into 77 districts and 753 local levels. This new structure of the country also affect in order to ensure production and availability of food, for better livelihood and employment of all groups of people for better access to food, education on food, health and nutrition. Better food utilization, supplementary water and health security to ensure holistic intake, to parallel empowerment of historically disadvantaged and vulnerable groups like women and indigenous communities, for example, for social protection and equitable distribution of food resources and agricultural production. Moving on from the MDGs, the SDGs 
have set new targets for food security in the signatory countries, including Nepal (LWF, 2017).

\section{Methods and Materials}

A number of studies related to food security have been reviewed to prepare this paper. Basically, Google Scholars, Pubmed and research gate are main search engine to extract related articles.

\section{Results and Discussion}

\section{Global Scenario}

Now in many countries primary risks to food security are at the country level due to the pandemic disease COVID-19 crisis unfolds, disruptions in domestic food supply chains, other shocks affecting food production, and loss of incomes and remittances are creating strong tensions and food security risks in many countries. The United Nations WFP, (2020) estimated 265 million people could face acute food insecurity by the end of 2020, up from 135 million people before the crisis, because of income and remittance losses. While, the number of people suffer from hunger is slowly increasing. According to the data of 2018 , more than 820 million people in the world were still hungry it shows the immense challenge of achieving the Zero Hunger target by 2030. Food insecurity and prevalence of undernourishment seems very high in almost all African sub-regions at almost 20\%. Even though the prevalence of food insecurity is below $7 \%$ in Latin America and the Caribbean, hunger is rising slowly. In the context of Asia, Western Asia seems to be more prevalent of food insecurity more than $12 \%$ of populations are undernourished and continuous increase since 2010. According to FAO, (2019) more than 2 billion people are expected lacking regular access to safe, nutritious and sufficient food. It includes 8 percent of the population in Northern America and Europe with considering all people in the world affected by moderate levels of food insecurity together with those who suffer from hunger. Economic downturns disproportionally cripple food security and nutrition where inequalities are greater. It is necessary to have in place economic and social policies to safeguard food security and nutrition. COVID-19 pandemic alarms a potential rise of food insecurity, many countries and organizations are mounting special efforts to keep agriculture safely running as an essential business, markets well supplied in affordable and nutritious food, and consumers still able to access and purchase food despite movement restrictions and income losses. Growing population of the world, changing food habit of the people (increased demand for animal protein), increased fuel prices (costly inputs/ transport), climate change and increased drought situations, need of grains for bio-fuel production and lower investment in agriculture sector 
are considered as the main reasons of global food insecurity. Recently, COVID-19 pandemic alarms a potential rise of food insecurity. Many countries and organizations are mounting special efforts to keep agriculture safely running as an essential business, markets well supplied in affordable and nutritious food and consumers still able to access and purchase food despite movement restrictions and income losses.

\section{Issues and causes of food insecurity in Nepal}

Food security status of Nepal is not only intensified by domestic causes (armed conflict, weak policies and institutional arrangements and poor governance) but also by external factors such as the interest of developed countries in developing ones in terms of use of resources, development investment and trade regulations. It is frequently observed that donors put down several conditions to give financial assistance (Panday, 2009). Being multidimensional in nature, other multi sector statistics such as agriculture, education, WASH, etc. are also very much related. The multi sector indicators work in bidirectional pathway meaning they are contributors to poor nutrition and food insecurity and can also be their manifestations. In Nepal, most of the development indicators continue to have wide gaps by region, sub-region and urban versus rural areas. Most serious consequence of food insecurity is malnutrition. Lower productivity on farms and in the labor market is a result of adult malnutrition. The malnourished women will give a birth to malnourished child, also cause fetal malnutrition. It is often observed that poor school enrollment, absenteeism, early dropout, and poor classroom performance are the major factors that result losses in productivity during adulthood causing childhood nutritional deficiencies. Efforts at achieving food security may also pose a heavy economic toll if households must spend most of their income on obtaining food. Presence of food insecurity probably suggests a high degree of vulnerability to a broad spectrum of consequences, including psychosocial dysfunction in children, socio-familial problems, and overall poor health status on a household level. Poor hygiene is the dark horse for infectious diseases and under-nutrition in the indigenous people. Hidden hunger is another form of hunger, which is more complicated and difficult to address by simple measure in many instances. It is generally triggered by macro level economic alignment and structural adjustment processes. In the long run, such economic processes systematically undermine the leverage and space of developing nation states to challenge the prevalence of negative implications of macro-economic reforms. Food security is achieved only when the four dimensions of the food security are available all time.

Food availability: For food security at first food should be available. Food availability is a physical presence of food in domestic production, commercial imports and food aid. Food availability addresses the "supply side" of food security. Food availability is determined by considering production, trade, stocks and transfers. 
Food accessibility: Household level of food security is not guarantee by the national and international food security. Food may be available in market in sufficient quantity but is not necessarily be in the access of people with low income and/or low purchasing power.

Food utilization: It refers to proper use of food. Food availability and accessibility cannot guarantee the food security. Good biological utilization of food is necessary for food security.

Stability: Food security can be achieved once availability, accessibility and utilization of food are ensured at all time and without significant fluctuation in the situation. Stability concerns about the sustainability of the satisfactory achievement of conditions related to all three aspects of food security discussed above (FAO, 2012).

\section{Impacts of natural disasters}

In every year of rainy season many people in western Nepal and terai region have been displaced by heavy rains, flash floods and landslides. Till date of $16^{\text {th }} \mathrm{July}$, at least 101 people are reported to dead, about 53 people are gone missing, and at least 96 people have been injured and about 616 families remain affected. More than 300 houses were damaged many people became homeless and lost their land. Due to the road infrastructure affected by disaster several communities remain isolated and the relief operations have been affected by bad weather. Thousands of people had lost their home and land (OHCHA, 2020). These disasters have a direct link with agriculture production and food security. Rice was one of the more severely affected crops from the long drought and a late monsoon.

\section{Impacts of armed conflict}

Population growth and food demand are vice-versa. Lack of accessibility, affordability and utilization (they also rely on production, processing, transportation, storage) further aggravate the situation. Because of the large outflow of the youth to foreign country, mostly to India which cause a scarcity of labor force in agricultural areas and ultimately affect the food production (Upreti \& Mueller-Boeker, 2010). Even though the remittances obtained from out migration, remote and rural areas were deprived of investments, were mostly retained in urban centers and towns for construction of buildings and other unproductive expenses. Banks were also not willing to invest in high-risk areas such as remote rural areas and where agriculture based livelihoods existed as rebels were declaring that they would not pay bank loans and they were destroying bank documents, etc. because of the conflict. During the conflict period the CPN (M) demanded that healthy and young individuals join them. This made rural households send their young children out of the village for livelihoods, 
and they forced them to take out of school. This also drastically impacted production spheres and supply chains (Ghale et al., 2010).

\section{Agriculture production}

Agriculture provides livelihoods for 68 percent of Nepal's population, accounting for 34 percent of the GDP. Nevertheless, Nepal struggles to produce an adequate supply of food for its citizens (USAID, 2020). Development of agriculture is very important because high food prices are increasing food insecurity and poverty are directly related to agricultural production. Developing economies have generally been described as dual economies with a traditional agricultural sector and a modern capitalist sector. It is essential to increase food productivity and production in developing countries to address food insecurity. Productivity is assumed to be lower in traditional agriculture than in the modern sector (Dethier \& Effenberger, 2012). This, however, requires finding viable solutions to a number of complex technical, institutional, and policy issues, including land markets, research on seeds and inputs, agricultural extension, credit, rural infrastructure, connection to markets, rural non-farm employment, trade policy and food price stabilization. Agriculture provides food, income, and jobs, and hence can be an engine of growth in agriculture-based developing countries and an effective tool to reduce poverty in transforming countries. Government of Nepal has also stepped forward to achieve food security and agriculture development, plan called 'The Agriculture Development Strategy (2015-2035)' and is road map with a ten years action plan that is expected to guide the agriculture sector of Nepal over the next 20 years and has been developed after completion of the long-term Agricultural Perspective plan.

\section{Food security and climate change}

Climate change and food security are both serious challenges which need to be addressed together. It is responsible for the all dimensions of the food security of vulnerable groups as well as different elements of food systems. Climate change has significant effect on agriculture and food security, creating new risks and challenges and exacerbating existing vulnerabilities from the local to the global level. The adverse effects of climate change can pose serious threats to food security especially to small scale food producers' lives and livelihoods, and to the progressive realization of the right to food in the context of national food security, and action is urgently needed. Inadequate disaster preparedness and response is a factor contributing to hunger, which affects all dimensions of food security (FAO, 2012).

\section{Governance}

Food security is affected by inadequate governance structures to ensure institutional stability, accountability, transparency, and rule of law and non- 
discrimination, which lead to taking of efficient decisions and underpin access to food and higher living standards. However, war, conflict and lack of security also play a major role in war, conflict and lack of security that play a major role in deepening hunger an d food insecurity; in fragile states, conflict, political instability and weak institutions intensify food insecurity (FAO, 2019).

\section{Economic and production issues}

Food security is affected by Poverty and inadequate access to food. These are a result of high unemployment and not enough decent work; inadequate social protection systems; unequal distribution of productive resources such as land, water, credit and knowledge; insufficient purchasing power for low-waged workers and the rural and urban poor; and low productivity of resources. Economy is directly related with the inadequate growth in agricultural production. Low agricultural production is due to insufficient international and national investment in the agricultural sector and rural infrastructure, particularly for small-scale food producers. Lack of an open, non-discriminatory, equitable, transparent multilateral trading system that promotes agriculture and rural development in developing countries could contribute to world food insecurity. Still in Nepal, there is insufficient access by producers to relevant technologies, inputs and institutions, very less investment in livestock production in agricultural systems. Other effects of climate change on agriculture are land degradation, increasing uncertainty about crop yields and the intensification of floods and droughts. Natural resources, ecosystem and biodiversity degradation also cause climate change and directly affect the agricultural production and so on food availability (FAO, 2019).

\section{Current status of food security in Nepal}

Nepal has improved food security status in recent years. According to NDHS, (2016), 4.6 million people are food-insecure, with 20 percent of households mildly food-insecure, 22 percent moderately food-insecure, and 10 percent severely foodinsecure. Erstwhile in 80s Nepal was a self- sufficient in food grains. Now, Nepal imports billions of food. In 1960s, the cereal yield in Nepal was one of the highest among the South Asian nations; yield in Nepal was $198 \%$ higher than Bangladesh, $212 \%$ higher than in Sri Lanka. But today the situation has completely reversed. Now, Nepal is comparatively lower than for most of its South Asian neighbors in average rice, wheat, and maize yield (Shrestha, 2018). The most serious consequence of food insecurity is malnutrition and it has a multitude of health and economic implications. National surveys over the past decades have consistently demonstrated high levels of child under nutrition plaguing the country. According to the report of Nepal Multiple Indicator Cluster Survey 2014, 37.4 percent of the Nepali children under five years 
were too short or stunted and 11.3 percent were too thin or wasted reflecting the extent of chronic and acute under nutrition respectively. According to the Food Security Monitoring Unit, Ministry of Agricultural Development and the World Food Program, Dhading, Gorkha, Kalikot, Mugu, Humla and Bajura were "highly food insecure". Nepal Food Security Bulletin states that "external assistance" is necessary for providing food and non-food demands. Highly food insecure population resembles people whose food consumption gaps are higher than normal. These people can meet minimum food needs only through "accelerated depletion of livelihood assets". Family size, gender, age and education levels, together with land ownership, household income, remittance and improved access to markets and roads seems to be strongly associated with food security (Regmi et al., 2019).

A big lesson learnt and encouraging achievements from MDGs, Nepal is committed to be part of the global Sustainable Development Agenda 2030. SDG 2 has major targets of ending hunger by 2030 and ensuring access by all people safe, nutritious and sufficient food all year round, ending all forms of malnutrition, doubling agricultural productivity, ensuring sustainable food production systems and maintaining by 2020 the genetic diversity of seeds, cultivated plants and farmed at the national, regional and international levels. Constitution of Nepal enshrined right to food as a basic need. SDG-2 has a target of reduction of undernourishment to 3 percent and prevalence of underweight children under five years of age to 5 percent by 2030. Gini-coefficient, a measure of income inequality, stood at 0.328 in 2010, a small improvement from 0.34 in 2004 but it has been getting steadily worse, and is now at 0.49 (NPC, 2017).

\section{COVID-19 and food security in Nepal}

Government of Nepal (GoN) ordered a national lockdown from the $24^{\text {th }}$ March, as a response to the spread of the novel corona virus (COVID-19) around the world, the urging people to stay at home and closing schools while restricting the operation of businesses and markets. The lockdown has since been extended through $7^{\text {th }}$ May. Food security is aggravated by COVID 19 because, during lockdown restriction of movement, closing down all the restaurant, production, markets, malls except emergency needs though they are steps designed to slow the spread of COVID-19 and to mitigate potentially devastating economic and social effects in Nepal, and reflect measures taken by most countries. While the restrictions on movement and activity in Nepal may be exacerbating food security issues across the country, they are steps designed to slow the spread of COVID-19, and to mitigate potentially devastating economic and social effects in Nepal, and reflect measures taken by most countries. The mostly affected sectors of Agriculture and Livestock, sectors are considered as to be poultry, dairy, vegetables and livestock production. Due to this lockdown causes 
difficulties in transportation have been pushing down demand for goods in urban settings in some cases and also decreased demand of milk by $60 \%$ due to difficulties in accessing markets and consumer anxiety. Sudurpaschim Province is reported to be insufficient by 68 percent on stock of food and nonfood commodities. Due to this confinement a majority of traders reported a low demand for both food and nonfood commodities. Due to this lockdown income of many people losses and difficulties in movement demand for food and non-food items has decreased compared to the previous week. Due to current COVID-19 crisis and lockdown, resulting in a limited movement of trucks and vehicles carrying goods, limited transportation services and supply of commodities have been affecting the food security (WFP, 2020).

Estimated stock market of Nepal is three month but not spread across the country uniformly. The sustained suspension of rice or other food good exports could affect food security in the country. Nepal imported a total of 25,770 metric ton of food goods from major trade posts in Biratnagar, Birgunj, Kakarbhitta and Bhairahawa. However, Humla, Bajura, Bajhang, Lamjung, Gorkha and Dhading districts seem to be hard to access markets with low food stock levels. Karnali province has organized at least one airlift to Humla district and has plans for more in Mugu and Dolpa districts. According to MoFAGA, 'most affected households' based on criteria are: wage labours working in informal sectors, like in construction work, agriculture, transport services, porters in tourism and other sector, garment industry, small trader, baby caretaker and deprived people with no caretakers (old age, disabled, pregnant, orphan, and people taking refuge in old age homes, monastery, church, temple, etc). In all mid-hill districts since the lockdown prices have increased by $30-60 \%$ on average in vegetable items in market and limited items are available (Shrestha \& Thapa, 2020).

\section{Program and policies for food insecurity reduction in Nepal MSNP II}

Building on the lessons learnt from MSNP (2013-2017), the Government of Nepal through the leadership of the National Planning Commission with the technical support of EU/ UNICEF, USAID, SUAAHARA, World Bank, WHO, WFP, FAO and Civil Society Organizations, formulated and developed Multi Sector Nutrition Plan II (2018-2022), which was endorsed and approved by the cabinet of ministers of the Government of Nepal on 19 November 2017. Targets of MSNP II are shown in table below.

Table 1: Targets of MSNP II for pulses, fruits and vegetables

\begin{tabular}{lccccc}
\hline \multicolumn{5}{c}{ Production in (1,000 tons) } \\
\hline Particulars & $75 / 76$ & $76 / 77$ & $77 / 78$ & $78 / 79$ & $79 / 80$ \\
\hline Cereal Production & 9515 & 9750 & 9414 & 9697 & 9987
\end{tabular}




\begin{tabular}{lccccc} 
Lentils & 329 & 335 & 342 & 349 & 356 \\
Fruits & 1181 & 1252 & 1327 & 1407 & 1492 \\
Vegetables & 4413 & 4678 & 4959 & 5256 & 5572 \\
Potato & 210 & 218 & 227 & 236 & 246 \\
\hline
\end{tabular}

\section{Sustainable development goals}

Nepal is committed to be part of the global Sustainable Development Agenda 2030, after a big lesson learnt and encouraging achievements from MDGs. SDG 2 has major targets of ending hunger by 2030 and ensuring access by all people safe, nutritious and sufficient food all year round, ending all forms of malnutrition, doubling agricultural productivity, ensuring sustainable food production systems and maintaining by 2020 the genetic diversity of seeds, cultivated plants and farmed at the national, regional and international levels.

\section{Agricultural Development Strategy}

Agricultural development strategy has targeted to improve nutritional status with the focus of long medium and short term goals which is shown in below.

Table 2: Indicators and Targets of Food and Nutrition security in the ADS

\begin{tabular}{|c|c|c|c|c|}
\hline Indicators & $\begin{array}{c}\text { Reference } \\
\text { Year } \\
(2010) \\
\%\end{array}$ & $\begin{array}{c}\text { Target } \\
\text { short } \\
\text { term } \\
\text { (5 yrs) } \\
\%\end{array}$ & $\begin{array}{c}\text { Target } \\
\text { medium } \\
\text { term } \\
(10 \text { yrs }) \\
\%\end{array}$ & $\begin{array}{c}\text { Target } \\
\text { long } \\
\text { term } \\
(20 \mathrm{yrs}) \\
\%\end{array}$ \\
\hline Food Poverty & 24 & 16 & 11 & 5 \\
\hline $\begin{array}{l}\text { Stunting (ht for age) among under } 5 \\
\text { children }\end{array}$ & 41.5 & 29 & 20 & 8 \\
\hline $\begin{array}{l}\text { Under weight (wt for age) among } \\
\text { under } 5 \text { children }\end{array}$ & 31.1 & 20 & 13 & 5 \\
\hline $\begin{array}{l}\text { Wasting (wt for ht) among under } 5 \\
\text { children }\end{array}$ & 13.7 & 5 & 2 & 1 \\
\hline $\begin{array}{l}\text { Women in reproductive age with } \\
\text { chronic energy deficiency (BMI) }\end{array}$ & 18.5 & 15 & 13 & 5 \\
\hline
\end{tabular}

Source: ADS, 2014

\section{The $15^{\text {th }}$ plan}

The $15^{\text {th }}$ plan of Nepal has its targets to address the food insecurities. Target of $15^{\text {th }}$ plan is shown in table below. 
Table 3: Target of $15^{\text {th }}$ periodic plan

\section{Indicators}

\section{Situation of Target of $15^{\text {th }}$ periodic}

2074/75 (\%) plan 2080/81 (\%)
Food insecurity

Severe food insecurity

Number of household which are secured of fundamental requirement of food.

Number of population that does not take minimum daily requirement of calorie
21

7.8

48.2

8.1
10

2

80

4

Source: (NPC, 2019)

\section{Conclusion}

Population of Nepal is growing rapidly. Nepalese agriculture cannot meet the growing food requirement. Due to this rapidly growing population it causes limited land resources and land productivity. Low production, distribution, poor access to food in remote areas, and low income are key factors causing food insecurity in Nepal. According to the different reports, children under five years were stunted and wasted reflecting the extent of chronic and acute under nutrition respectively. Prevalence of severely food insecure population in rural area is $12 \%$ more than urban areas $9 \%$. Due to COVID-19 pandemic, food insecurity has been increased due to restriction of movement, closing down all the restaurant, production, markets and malls. To address the food insecurity problem, higher economic growth, equitable distribution, a mix of policies such as effective implementation of anti-poverty programs, improving health education and employment are necessary. Hunger and food insecurity eradication requires the means for enthusiastic political association and deliberation. Research, extension, and capacity building programs should be pro-poor and women focused. The government must provide top priority to irrigation agricultural production, and road links in order to increase production, distribution, and access to food.

\section{References}

Adhikari, J. (2010). Food Insecurity, Conflict and Livelihood Threats in Nepal. In B. R. Upreti \& U. Müller-Böker (Eds.), Livelihood insecurity and social conflict in Nepal. South Asia Regional Coordination Office, Swiss National Centre of Competence in Research (SNCCR) North-South, Kathmandu, Nepal.

ADS. (2014). Agriculture Development Strategy (ADS) 2014. http://www.nnfsp.gov. $\mathrm{np} /$ PortalContent.aspx $\underset{\text { ¿Doctype }}{ }=$ Resources $\& I D=61$ 
Dethier, J. J., \& Effenberger, A. (2012). Agriculture and development: A brief review of the literature. Economic Systems, 36(2), 175-205. https://doi.org/10.1016/j. ecosys.2011.09.003

FAO. (1996). The Rome declaration on world food security. Population Development Review, 22, 807-809.

FAO. (2012a). Climate Change and Food Security.

FAO. (2012b). Committee on World Food Security (CFS) Global Strategic Framework for Food Security \& Nutrition (GSF).

FAO. (2019). Food security and nutrition in the world the state of. www.fao. org/publications

Ghale, Y., Upreti, B. R., \& Ghimire, S. (2010). Fostering Sustainable Development in South Asia Food Insecurity and Conflict in Nepal. Islamabad: Sustainable Development Policy Institute-Pakistan and Sang-e-Meel Publication.

LWF. (2017). Participatory Food Security Policy Mapping in Nepal LWF Nepal with support from RtFN.

MoALD, CBS, WFP, \& FAO. (2018). SDGs and food insecurity in Karnali: Results from the food insecurity experience scale. Ministry of Agriculture and Livestock Development, Central Bureau of Statistics, World Food Programme and Food and Agriculture Organization, Kathmandu, Nepal.

MoH. (2017). Nepal Demographic and Health Survey 2016. Ministry of Health, Kathmandu, Nepal.

NDHS. (2016). Nepal Demographic and Health Survey.

NPC. (2017). Nepal's Sustainable Development Goals Baseline Report National Planning Commission, Government of Nepal. www.npc.gov.np

NPC. (2019). 15th Five Year Development Plan (2019/20-2023/24) : Health and Nutrition. https://www.publichealthupdate.com/15th-five-year-developmentplan-2019-20-2023-24-health-and-nutrition/

OHCHA. (2020). Asia and Pacific; Weekly Regional Humanitarian Snapshot.

Panday, D. R. (2009). 'Nepal's failed development: Reflections on the mission and the melodies.' Nepal South Asia Centre, Kathmandu.

Regmi, H. R., Joshi, G. R., Sapkota, R. P., \& Thapa, S. (2019). Factors influencing food insecurity in nepal. Journal of Institute of Science and Technology, 24(2), 22-29.

Shrestha, P. (2018). Nepal faces food-security difficulties - South Asia Journal. SOUTH ASIAN JOURNAL. http://southasiajournal.net/nepal-faces-foodsecurity-difficulties/ 
Shrestha, P., \& Thapa, S. (2020). Nepal COVID-19 Food Security \& Vulnerability. https://www.wfp.org/publications/wfp-nepal-food-security-and-vulnerabilityupdate-no-2-3

Upreti, B. R., \& Mueller-Boeker, U. (2010). Livelihood insecurity and social conflict in Nepal. South Asia Regional Coordination Office of the Swiss National Centre of Competence in Research (North-South), Kathmandu.

USAID. (2020). Agriculture and Food Security | Nepal | U.S. Agency for International Development. https://www.usaid.gov/nepal/agriculture-and-food-security

WFP. (2014). United Nations World Food Programme (WFP) - WFP.org. https://www. wfp.org/

WFP. (2019). Nepal World Food Programme. World Food Program. https://www.wfp. org/countries/nepal

WFP. (2020). Nepal COVID-19: Food Security \& Vulnerability Update 3 - Nepal. https://reliefweb.int/report/nepal/nepal-covid-19-food-security-vulnerabilityupdate-3 